Supporting Information for

\title{
Charge Transfer through Modified Peptide Nucleic Acids
}

Emil Wierzbinski, ${ }^{\S}$ Arnie de Leon, ${ }^{\#}$ Kathryn L. Davis, ${ }^{\S}$ Silvia Bezer, ${ }^{\#}$ Matthäus A. Wolak, Matthew J. Kofke, ${ }^{\S}$ Rudy Schlaf, ${ }^{\ddagger}$ Catalina Achim, ${ }^{\# *}$ David H. Waldeck ${ }^{{ }^{*}}$

${ }^{\S}$ Department of Chemistry, University of Pittsburgh, Pittsburgh, PA, 15260

\#Department of Chemistry, Carnegie Mellon University, Pittsburgh, PA, 15213

${ }^{\ddagger}$ Department of Electrical Engineering, University of South Florida, Tampa, Fl, 33620

*Indicates corresponding authors, E-mail: achim@cmu.edu, dave@pitt.edu

Table S1. Calculated masses of PNA molecules and corresponding m/z observed from MALDI-ToF MS (reflection mode, $\alpha$-cyano-4-hydroxycinnamic acid matrix, laser intensity 1700).

\begin{tabular}{|c|c|c|}
\hline \multirow{2}{*}{ PNA Strand } & \multicolumn{2}{|c|}{ MALDI-ToF MS Data $(\mathrm{m} / \mathrm{z})$} \\
\hline & Calculated & Found \\
\hline Cys-TCACTAGATG-Fc & 3041.8 & 3039.6 \\
\hline Cys-TCACTAGATG & 2829.8 & 2831.6 \\
\hline Cys-CATCTAGTGA & 2829.8 & 2830.2 \\
\hline Lys-CATCTAGTGA & 2854.8 & 2855.8 \\
\hline Lys-CATCCAGTGA & 2839.8 & 2842.2 \\
\hline Cys- CATCCAGTGA & 2829.8 & 2828.6 \\
\hline Cys-TCACT-Bpy-GATG-Fc & 3062.9 & 3060.8 \\
\hline Cys-TCACT-Bpy-GATG & 2850.9 & 2849.9 \\
\hline Cys-CATC-Bpy-AGTGA & 2859.9 & 2858.8 \\
\hline Lys-CATC-Bpy-AGTGA & 2884.9 & 2883.4 \\
\hline Cys-TCACT-Bk-GATG-Fc & 2908.7 & 2907.4 \\
\hline Lys-CATC-Bk-AGTGA & 2730.7 & 2730.5 \\
\hline
\end{tabular}


(A)

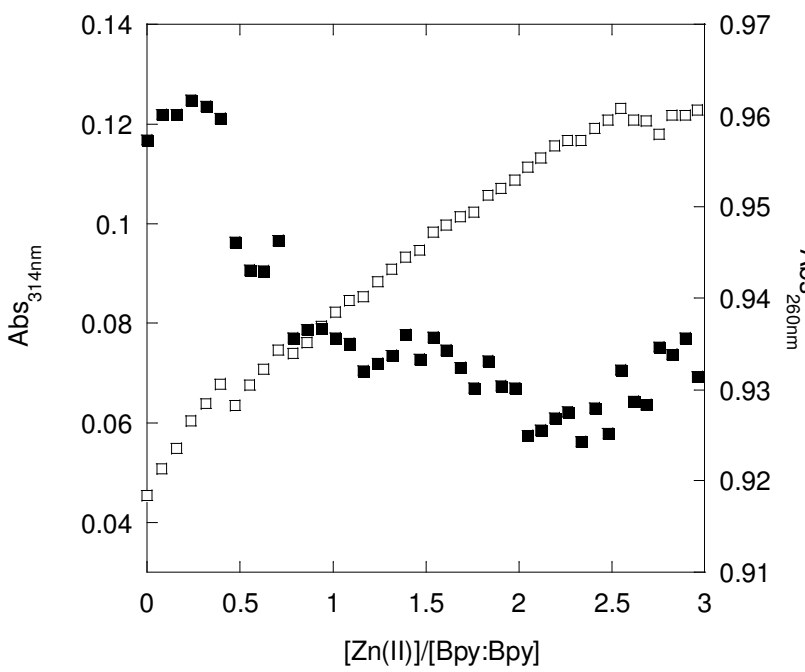

(B)

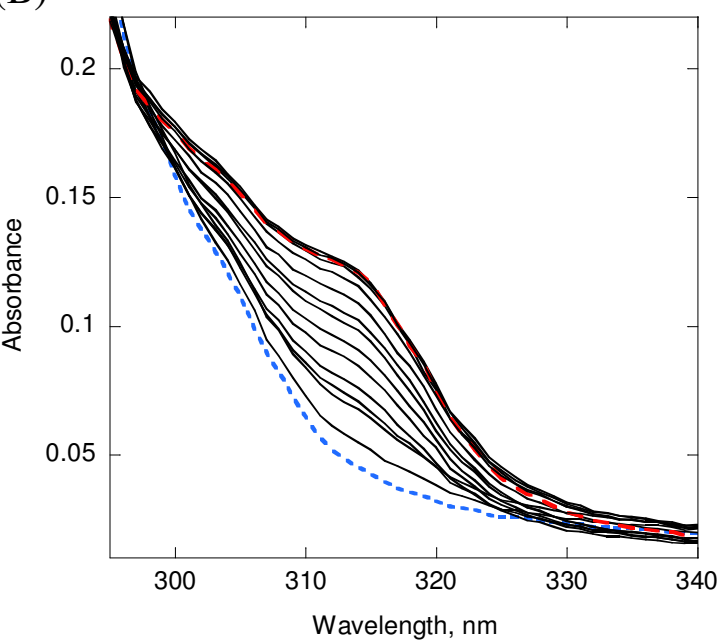

Figure S1. (A) Titration curves at 260nm (close squares) and $314 \mathrm{~nm}$ (open squares) and (B) Magnified region of the UV spectra (figure 3A) from 295 to $340 \mathrm{~nm}$ for a $5 \mu \mathrm{M}$ solution of Bpy:Bpy PNA titrated with $\mathrm{Zn}^{2+}$. Dashed lines indicate the UV spectra at the beginning (blue) and at the end of the titration (red). 